mained sound. Patient generally slept about six hours out of the twenty-four, but he wakened two or three times an hour. Intelligence was perfectly preserved, and he was ordinarily quite cheerful, and took a remarkably shrewd and eager interest in external affairs. His hearing was good. He could move his tongue freely, and his speech was like that of any healthy person speaking with closed teeth. A well-marked systolic murmur was audible at the apex and base of the heart, and along the sternum. Otherwise, under ordinary circumstances, nothing noteworthy was detected in the front of the chest. There was nothing of importance, and in particular, no rheumatism, in the family history.

The patient suffered occasionally from a feverish cold which, though it would have been trifling to an ordinary individual, was a formidable thing to him. The power of coughing and expectorating was extremely limited, and the bronchial secretion was apt to cause great distress before it could be coughed up. His last illness set in on January ist, 1900, with pain in the left side and cough. Pleural friction and bronchial râles were subsequently heard. There was retention of urine for some days in this attack. Death took place on January 6th, apparently through accumulation of bronchial secretion. Permission was refused even for an external examination of the body after death.

As the case came under my observation only after the active disease had died out, and as there was no necropsy, it would not be well for me to dogmatise too much as to the pathology of the affection. It appears, however, to correspond to the subacute type of the very rare disease described by Dr. Joseph Griffiths in I 897 as " universal bony ankylosis or arthritis ossificans.". Dr. Griffiths was able to collect twenty cases. ${ }^{1}$ Cases of this kind correspond to what are popularly known as "ossified" men."

1 Journal REFERENCES

of Patholngy and Bacteriology, 1897, iv, $468-483.22$ Gould and
Pyle, Anomalies and Curiosities of Medicine, $787-8$.

\section{STRANGULATION OF MECKEL'S DIVERTICULUM.}

BY KEITH CAMPBELL, M.D.EDIN., D.P.H.,

Assistant Medical Officer, Glamorgan County Asylum, Bridgend.

As a corollary to the Notes on the Anatomy and Surgery of Meckel's Diverticulum, by Mr. George A. Clarkson, in the British Medical Journal of March 23rd, the following notes of a case of intestinal obstruction due to strangulation of this diverticulum may be of surgical as well as of pathological interest.

The patient was an old and very feeble man of over 70 , suffering from senile dementia, who had long been known to have a right-sided oblique inguinal hernia which was always reducible. When the hernia was rethe the abdominal cavity there stinl remained,in the interval beits close connection with the cord was diagnosed as a lydrocele of the

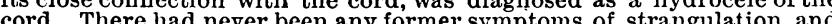
cord. There had never been any former symptoms of strangulation, and there was no appearance of swelling at any of the other hernial regions He was always inclined to be constipated. On the occasion now relerred to he had not had a motion for thirty-six hours. Castor oil was given but without result within twelve hours. Owing to his mental state he did not give any other marked indication of abdominal obstruction. On the second day, however, he vomited once or twice, and the hernial regions were examined. The right inguinal region was as usual, and there was fulness was noticed, but no subjective symptoms were elicited. He liad enemata, with slight effect, on the evening of the second day. The temperature was $100^{\circ} \mathrm{F}$., and the pulse, which was always bad, began to intermit. He vomited again once or twice in the early part of the night, and collapsed suddenly in the early morning. When seen then he was still not wholly unconscious, and he moaned when the abdomen was palpated. It was noticed also that the left thigh was flexed, and there was a more distinct swelling, rather tense by this time, over the left femoral area. The diagnosis come to was strangulated left femoral hernia with peritonitis. The question of operation was discussed in consultation, but
decided against on account of the patient's general condition. He died late on the evening of the third day.

Necropsy.-Left femoral region: On dissecting from without the crural canal was found occupied by an indurated gland, attached at its lower extremity to the superficial tissues of the leg by lymphatics and fibrous tissue. Above, it was adherent to what appeared to be the sac of a hernia evidently containing bowel. This was constricted, not very tightly, just at Poupart's ligament. On opening into the sac just below Poupart's ligament, it was found to be adherent to the gut at its lower part; also the gut could not be pulled further down, thoigh the constriction at the neck of the sac was relieved. The piece of gut did not look like a knuckle. In the right inguinal region a dissection was made from the internal ring to the lower part of the scrotum, exposing the whole length of the cordswelling at the lower part of the cord, separate from the testicle, evidently crstic, which on puncture yielded ro ir.uclims of a translucent slightly blood-stained flu:d and collapsed. The upper part of the canal contained what was obviously a hernial sic, but no gut. The abdomen was then opened the right anteriol superior spinc to join it. There was found to be con.
siderable recent adhesive peritonitis, the omentum being matted and adriclit internal ring from this a spect a well-marked hernial sac was found

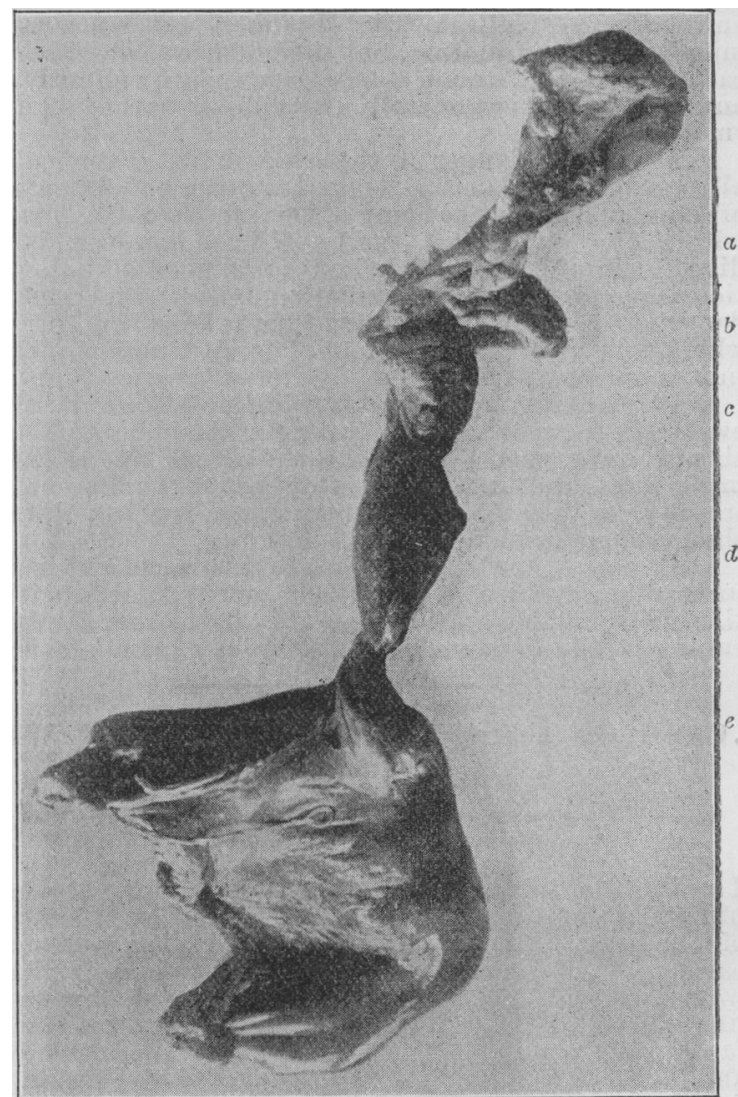

$a$, Lymplatics and superficic 1 fascia of thigh; $b$, indurated gland; $c$, the blind end of the diverticulum which was adherent to the gland; $d$, deeply congested part marked off by the twisting of the diverticulum in two places; $e$, the origin of the diverticulum from the ileum, which is seen with part of its mesentery preserved.

in the upper part of the inguinal canal, measuring about 3 inches in lepth. It contained no gut, and the internal ring was abnormally large. The small intestine was considerably distended, and part. On tracing the piece of bowel from the left crural canal upwards, was found to join the lleum at right angles, being astached fuly $2 \frac{3}{4}$ feet from the ileo-crecal valve, and arising from the lower and anterior aspect of the intestinal tube. In circumference it was smaller than the ileum and at its blind end, adherent to the gland in the canal, no trace of anything like a fibrous cord could be found. (See figure.) The whole surface fict of its being in a state of strangulation. It measured about $4 \frac{1}{4}$ ins. fact of its being in a state of strangulation. It measured about 44 ins. long. The sac of parietal peritoneum, which had ibeen pushed into the canal and to the gland situated in it. It was also adherent to the diverticulum itself, but could be fairly easily separated. There was a distinctly constricted ring, evidently just on the point of perforation, where the diverticulum was gripped by Gimbernat's ligament. Then came an intensely congested portion, about 2 ins. long, marked off above by constriction where the diverticulum was twisted one and a-half time on its longitudinal axis, and below by a slighter twisting. The part between the twists was quite black, but still glistening. The proximal end of the diverticulum was congested in a less degree. There was fluid in the pouch of Douglas.

Apart from the diagnostic difficulties of the condition, and the fact that it would have been impossible to complete the operation for relief of the strangulation, or even to have been sure of the pathological anatomy without opening the abdomen, the following points are interesting :

I That this fœtal relic should have persisted in such considerable proportions. Its point of origin from the intestine was within the average distance from the ileo-cæcal valve, but the diverticulum was $1 \frac{1}{4}$ inch longer than the usual limit 
of length mentioned by Mr. Clarkson. It was supplied with blood by an anastomosis of vessels from the coats of the ileum and communicated freely with the ileum through a large opening. Arising as it did from the lower and anterior aspect of the gut there was no mesenteric attachment, and before it had adhered to the parietal peritoneum in the crural canal, it must have been freely movable in the abdominal cavity. By an unfortunate mistake the specimen was not available for microscopic examination, but though it was of rather smaller calibre than the ileum, its walls were only slightly thinner, and its appearance generally was similar to that of a piece of small intestine.

2. The chief danger of these persistent diverticula is usually considered to be the risk to the other abdominal contents of strangulation on account of the presence of a fibrous band within the abdominal cavity. Here, however, it was the diverticulum itself which had established pathological relationships, producing strangulation of itself, and secondary inflammatory results on the contiguous bowel and peritoneum, which gave all the signs of complete obstruction of the bowel in its continuity.

3. It is interesting from a surgical point of view that this, evidently the most freely movable of the abdominal contents, should have been forced into the canal by the intra-abdominal pressure, and that, having become adherent at its extremity, a volvulus, apparently secondary in point of time, should have formed.

4. It is also curious to think that this patient had lived a long and active life, without any inconvenience arising from this irresponsible appendage in his abdominal cavity, only to succumb at last to results arising from its persistence.

\section{CASE OF CANCER OF THE LARYNX WITH A LONG COURSE.}

By E. DONALDSON, B.A.T.C.D., L.R.C.S.I., Surgeon Londonderry Eye, Ear, and Throat Hospital.

I AM induced to publish the main facts of this case on account of its long duration, nine years and one month, and because of the great difficulty experienced in diagnosis during the earlier part of the illness. For a long time a benign growth was diagnosed, and the disease was allowed to run its course unmodified by the more radical methods of treatment. The fact I wish to emphasise is that a warty laryngeal growth in an elderly person may present symptoms of a benign tumour for about eight years, and in the end turn out to be malignant.

History. Miss S. first complained of hoarseness in December, 1888 . In the spring of $x 889$ she was under the care of a well-known surgeon, skilled in the use of the laryngoscope, for seven weeks. He found a sessile warty growth at the anterior part of the left vocal cord, which he removed with found to be of a non-malignant nature. The surgeon on June 28th, 1880. made a sketch of the larynx before and after treatment. There was only treatment. She then lost her hoarseness and remained well until November, 1890 , when the hoarseness returned and occasional slight diffculty in breathing was felt.

State on Examination. - I saw her for the first time on December ${ }_{3} \mathrm{rd}, 1800$ She was then 58 years old. I found that the wart had returned on the anterior part of the left vocal cord; it was pale in colour, sessile, and occupied nearly one-third of the cord. From this on she remained hoarse, and did not again completely recover her voice. In November 1892, I found a growth on the right cord opposite that on the left. I could not say that there was any marked immobility of the cords. From time to time the growths were touched with ethylate of sodium, absolute alcoliol, and chloride of zinc solution.

Progress.-Progress was very slow indeed, and there was little difference from month to month. In 1896 she was again under the care of the surgeon who originally treated her, and he was obliged on November ${ }_{3}$ rd of that year to perform tracheotomy on account of difficulty of breathing. After this operation she again came under my care, wearing a tracheotomy tube. The condition of the larynx did not improve, but became progressively worse. At the end of December, 1896, the left ary-epiglottic fold had become much swollen. There was a mere chink between the growths on the cords. I was now certain that the disease was malignant, and I commutch whe care she had been. He wrote to say the his arynx would not prolong life. In February, $\mathbf{8 9 7}$, I found both ary-epigot colds swoll not make any attempt at speaking. Swallowing was decidedly painful. She wrote that she could take a big drink better than a sip, and could swallow best with the head raised. She liked "to bolt" her milk. In May, 1897, there was a slight discharge of blood through the tube and round it; wasting and loss of strength were noticeable, but anæmia was came through the tracheotomy tube. She emaciated rapidly towards the

end, and died of exhaustion on January 22nd, 1898 . Pathol dicroscopeck at the opening into the posite the tracheotomy wound there was a sloughy opening into the osophagus. The larynx was so disorganised as to be recognisable. Round the trachentomy opening the larynx and the

The microscope proved that the growth was an epithelioma. In regard to whether it was of this nature from the beginning, or became malignant some time during the nine odd years of its existence, I leave each one to form his own opinion.

\section{FURUNCULOSIS OF THE EXTERNAL AUDITORY} CANAL SIMUlatiNg MASTOID PERIOSTITIS.

By JAMES GALBRAITH CONNAL, M.B., F.F.P.S.G., Lecturer on Aural Surgery, Anderson's College Medical School ; Assistant
Surgeon, Glasgow Ear Hospital, etc.

THE leading local symptoms of furunculosis of the external auditory canal-namely, pain in the ear, dulness of hearing, tinnitus, sometimes giddiness, and occasionally a scanty discharge from the ear-are well known. Of the constitutional symptoms a moderate degree of febrile reaction is common. There is, however, another type of case where, in addition to the above-mentioned symptoms, we have an cedematous swelling over the mastoid process, which is confusing and apt to lead to errors in diagnosis. The error is pardonable, for the clinical picture is that of a mastoid periostitis; so much so, that apart from a local examination of the external auditory canal a correct diagnosis and prognosis is hardly possible.

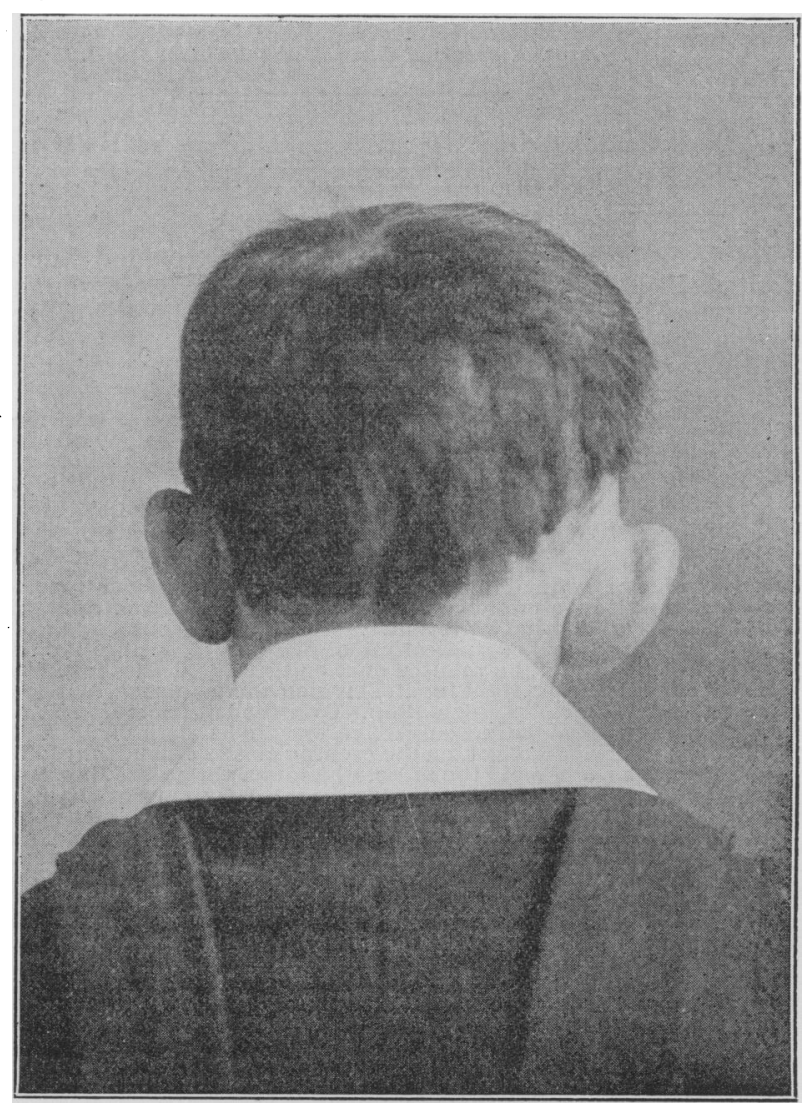

Fig. x.-Boy, 8 years of age, with fil uncle in the right external auditory canal, swelling over mastoid displacing the auricle downwards and forwards.

Anatomical Considerations.-To rightly understand this condition the anatomical structure of the outer ear must be borne 